\title{
Implementasi Metode Hazard Identification Risk Assessment and Risk Control Guna Peningkatan Keselamatan dan Kesehatan Karyawan di PT ABC
}

\author{
Alfina Fitri Damayanti ${ }^{1 *}$, Nina Aini Mahbubah ${ }^{2 *}$ \\ ${ }^{* 1}$ Program Studi Teknik Industri, Fakultas Teknik, Universitas Muhammadiyah Gresik \\ Jl. Sumatera 101 GKB, Randuagung Gresik 61121, Indonesia \\ *Koresponden email: n.mahbubah@umg.ac.id, alfina_170601@umg.ac.id
}

Diterima : 29 Desember 2020

Disetujui : 28 Januari 2021

\begin{abstract}
Zero accident was considered as the primary occupational health and safety value in manufacturing and service enterprises. PT. ABC provided electrical and instrument services, including a low-voltage installation, high-voltage installation and an instrument installation. This company is known to excellent electricity and instrument service providers across the country. Moreover, men's power is used as a primary source to maintain these kind of services. Installation projects depend not only on the high working speed, but also on high working accuracy within certain timeframes. As a result, work accidents have occurred with a classification varying from minor to fatal accidents. The purpose of this research is to identify potential hazards to assess risk levels and obtain recommendations for preventing accident. The HIRARC method is employed as a research approach. This research is initiated through Hazard Identification, Risk Assessment and Risk Control. This research identified that two hazards were classified as extreme risk, three hazards as high- risk, eight hazards as moderate risk, and two hazards have been identified as low risk. Furthermore, a number of action lists have been suggested in order to minimize accident rates and finally the working conditions are designed to maintain zero accidents.
\end{abstract}

Keywords: HIRARC, potential hazards, risk level, risk control, K3

\begin{abstract}
Abstrak
Zero accident telah dianggap sebagai nilai utama dalam hal keselamatan dan kesehatan kerja. Sebagai salah satu perusahaan besar, PT. ABC bergerak di bidang jasa konstruksi di department of electrical \& instrumen yang memiliki 3 jenis pekerjaan yaitu : instalasi tegangan rendah, instalasi tegangan tinggi dan instalasi instrumen. PT. ABC berpengalaman mengerjakan project yang tersebar di seluruh wilayah Indonesia Sebagai perusahaan yang memiliki ketergantungan terhadap tenaga kerja dalam melakukan aktivitas kerja, terjadinya kecelakaan kerja yang mengakibkan cedera menjadikan perusahaan harus melakukan identifikasi terhadap potensi bahaya yang timbul sehingga tingkat risiko dapat dihindari dan peluang terjadinya dapat direduksi. Tujuan penelitian yaitu mengidentifikasi bahaya, menghitung level risiko serta memberikan rekomendasi untuk menanggulangi potensi bahaya menggunakan pendekatan Hazard Identification, Risk Assesment And Risk Control. Hasil penelitian menunjukkan bahwa terdapat dua bahaya termasuk kategori sangat berbahaya, tiga bahaya termasuk dalam kategori risiko bahaya tinggi, delapan bahaya termasuk dalam kategori sedang, dan dua bahaya termasuk dalam kategori risiko rendah. Langkah-langkah pengendalian risiko diusulkan untuk bahaya dengan level risiko sangat tinggi, level risiko tinggi, level risiko sedang dan level risiko rendah berdasar diharapkan mampu meminimalisir terjadinya tingkat kecelakaan kerja dan tenaga kerja selalu di kondisi aman, selamat dan sehat dari bahaya kecelakaan kerja.
\end{abstract}

Kata Kunci: HIRARC, potensi bahaya, level risiko, pengendalian risiko, K3

\section{Pendahuluan}

Zero accident merupakan salah satu pencapaian tertinggi dalam pengelolaan kesehatan dan keselamatan kerja pada industri manufaktur maupun industri jasa. Kualitas sumber daya manusia berperan penting dalam mencapai kondisi pelaksanaan pekerjaan tanpa adanya cedera tersebut. Salah satu usaha yang bisa dilakukan dalam peningkatan kualitas SDM dapat dilakukan dengan mengelola Kesehatan serta Keselamatan kerja (SMK3). Pengelolaan SMK3 adalah usaha untuk mengidentifikasi risiko atau bahaya pekerjaan sehingga risiko kerja dapat dilakukan perbaikan atau direduksi dengan metode yang ada. Implementasi SMK3 menguntungkan tidak hanya bagi karyawan, tetapi bagi manajemen perusahaan juga menguntungkan dan memberikan nilai tambah perusahaan dmata pelangg an 
[1]. Pemerintah Indonesia mengatur perihal SMK3 dalam UU No. 1, 1970 perihal Keselamatan dan kesehatan kerja (K3), serta mendefinisikan K3 sebagai, 'setiap pekerja berhak menerima perlindungan kesehatan dan keselamatan kerja'. [2].

K3 adalah kebijakan pemerintah dalam mengatur pemilik usaha agar melindungi semua karyawan agar terhindar dari kecelakaan dan gangguan kesehatan sebagai akibat dari suatu aktivitas pekerjaan [3]. [4] mengklasifikasikan 2 faktor penyebab kecelakaan kerja yaitu faktor tindakan tidak aman, seperti kesalahan pemakaian APD, salah mendefinisikan SOP, kurang pengalaman, dan faktor kedua adalah kondisi kerja tidak aman, seperti lingkungan kerja terpapar radiasi, peralatan yang tidak layak, ada api ditempat kerja. Risiko didefinisikan sebagai sesuatu yang selalu terikat hampir disetiap kegiatan kerja, seperti pada aspek keselamatan dan kesehatan kerja (K3), jika ditemukan bahaya yang tinggi maka harus diperhatikan karena risiko tersebut akan sangat mengancam keselamatan karyawan ditempat kerja [5]. Maka dari itu pentingnya konsep K3 harus dibiasakan dalam penerapan dan kedisiplinan yang dimulai dari diri sendiri agar selalu terpelihara kondisi fisiknya.

PT. ABC diklasifikasikan sebagai suatu usaha jasa instalasi department of electrical \& instrumen. Kini perusahaan tersebut sudah sukses ditandai dengan pengalaman mengerjakan project yang tersebar di seluruh wilayah Indonesia. Dimana dengan project yang tersebar di berbagai daerah tersebut tidak menutup kemungkinan perusahaan seringkali menghadapi masalah dalam menyelesaikan proyek, diantaranya yaitu mengelola dan mengontrol karyawan (SDM) agar tetap aman, selamat dan sehat karena lokasi proyek yang berjauhan dan terpencar-pencar diberbagai daerah.

Pada department of electrical \& instrumen di PT ABC terdapat 3 jenis pekerjaan, yaitu : instalasi tegangan rendah, instalasi tegangan tinggi dan instalasi instrumen, dengan pekerjaan di bidang tersebut maka karyawan akan berhubungan langsung dengan jaringan listrik tegangan tinggi yang dapat membahayakan keselamatan fisik pekerja. Maka dari itu peran kinerja SDM di perusahaan tidak terlepas dari bahaya kecelakaan kerja. Dampak dari kecelakaan kerja akan mengakibatkan karyawan mengalami cedera ringan, berat hingga kematian dalam kurun waktu tertentu. Menurut ref. [6] industri kontruksi dikenal sebagai suatu jenis pekerjaan yang memiliki risiko sangat serius bagi karyawan di lapangan. Maka dari itu pada perusahaan jasa konstruksi seperti PT. ABC memerlukan sistem manajemen risiko untuk meminimalisir kecelakaan kerja sehingga tenaga kerja tetap dalam kondisi aman dan sehat.

Berdasarkan hasil observasi dan wawancara terhadap kepala departemen didapatkan bahwa masih sering terjadi kecelakaan kerja pada bagian pelayanan jasa di bidang electrical \& instrumen dimana penyebab kecelakaan kerja terjadi karena human error, cara kerja yang salah, lingkungan kerja yang tidak aman, pemakaian APD yang kurang tepat. Dengan masih ditemukannya kecelakaan kerja yang mengalami luka ringan dan luka berat merupakan indikasi bahwa penerapan K3 harus selalu dilakukan perbaikan.

Adapun terdapat penelitian yang pernah dilakukan mengenai analisis kecelakaan dan keselamatan kerja untuk mengurangi tingkat kecelakaan kerja yaitu pada penelitian oleh ref. [7] mengevaluasi risiko dan tingkatan bahaya pada karyawan bagian pengecoran menggunakan pendekatan HIRARC. Temuan penelitian tersebut didapatkan bahwa mayoritas risiko sangat tinggi terjadi pada tiga tahapan proses produksi dan minor risiko berbahaya level sedang terjadi pada dua tahapan proses produksi pengecoran tersebut.

Sesuai pemaparan latar belakang permasalahan, untuk menjunjung implementasi dari pengelolaan SMK3, maka diperlukan suatu penelitian berbasis pendekatan HIRARC. Metode ini berisi serangkaian implementasi K3 untuk mencegah dan meminimalisir kejadian yang menimbulkan gangguan keselamatan karyawan dengan cara melakukan klarifikasi dan perhitungan potensi risiko kejadian yang membahayakan keselammatan pekerja sekaligus merekomendasikan langkah-langkah yang dapat dilakukan guna mengeliminasi kondisi berbahaya tersebut. [8]. Penelitian ini bertujuan untuk mengidentifikasi potensi risiko bahaya, melakukan perhitungan level risiko bahaya berdasarkan identifikasi tersebut dan menganalisis dan mengusulkan tindakan perbaikan guna meningkatkan keselamatan dan kesehatan karyawan dalam melakukan aktivitas pekerjaan.

\section{Metode Penelitian}

Menurut [9] sebagai rujukan pendekatan pengelolaan SMK3 dan diadaptasi di seluruh negara di dunia menyebutkan pada klausal 4.3.1 bahwa manajemen risiko merupakan elemen inti dari konsep manajemen K3, dimana pada semua entitas dan manajemen perusahaan diharapkan mengelola, mengimplementasikan dan menjaga peraturan guna identifikasi bahaya dari kegiatan aktivitas pekerjaan sedang terjadi, assessment risiko serta pemilihan pengendalian atau dalam kata lain meminta bagi tiap organisasi ketika mengimplementasikan SMK3 berbasis HIRARC dari semua tahapan aktivitas yang ada. 
HIRARC merupakan proses identifikasi risiko disemua kondisi kemudian melakukan proses penilaian risiko untuk mengklasterkan tingkatan bahaya sekaligus upaya pengendalian yang diharapkan dapat melakukan pengawasan dan penurunan tingkat kecelakaan kerja yang terjadi [10].

Berikut merupakan langkah-langkah manajemen risiko menggunakan metode HIRARC, yaitu :

1. Identifikasi Bahaya (Hazard Identification), yaitu langkah untuk mengamati setiap area kerja serta identifikasi potensi bahaya yang ada disetiap tahapan kegiatan kerja yang meliputi semua situasi, kejadian serta sistem kerja yang mungkin menimbulkan kecelakaan [11].

2. Penilaian Risiko (Risk Assessment), yaitu langkah untuk menilai risiko dengan menentukan tingkat risiko dari bahaya yang teridentifikasi untuk memastikan bahwa kontrol risiko dari kegiatan yang dilakukan berada pada kategori yang dapat diterima [12].

Penilaian risiko dilakukan atas dasar Standards Australia License/New Zealand Standard 4360:1999. Pada proses penilaian risiko terdapat 2 parameter yang digunakan, pertama mengklarifikasi kejadian dan potensi kejadian risiko (Likelihood) dan peringkat besar kecilnya bahaya (consequence) tersebut. Untuk kriteria Likelihood disajikan di Tabel 1, selanjutnya tingkatan consequence ditunjukkan pada Tabel 2.

Tabel 1. Kriteria tingkat kemungkinan (Likelihood)

\begin{tabular}{ccl}
\hline Tingkat & Aturan & \multicolumn{1}{c}{ Penjelasan } \\
\hline 5 & Almost Certain & $\begin{array}{l}\text { Suatu insiden yang pasti akan terjadi disemua kondisi } \\
\text { (Terdapat } \geq 1 \text { kejadian dalam sehari) } \\
\text { Suatu insiden yang sangat mungkin akan terjadi (berkala) } \\
\text { dihampir semua kondisi } \\
\text { (Terdapat } \geq 1 \text { kejadian dalam seminggu) }\end{array}$ \\
3 & Possible & $\begin{array}{l}\text { Suatu insiden yang akan terjadi dibeberapa kondisi tertentu } \\
\text { (Terdapat } \geq 1 \text { kejadian dalam sebulan) } \\
\text { Suatu insiden yang mungkin terjadi dibeberapa kondisi tertentu, } \\
\text { namun kemungkinan terjadinya kecil (jarang) } \\
\text { (Terdapat } \geq 1 \text { kejadian dalam setahun) } \\
\text { Suatu insiden yang mungkin terjadi hanya disuatu kondisi } \\
\text { khusus/luar biasa/ setelah bertahun-tahun } \\
\text { (Terdapat }<1 \text { kejadian dalam setahun) }\end{array}$ \\
\hline
\end{tabular}

Sumber : AS/NZS 4360 (1999)

Tabel 2. Kriteria tingkat keparahan (Consequence)

\begin{tabular}{|c|c|c|}
\hline Tingkat & Aturan & Penjelasan \\
\hline 1 & Insignificant & Tidak Ada Cidera - kehilangan nilai uang rendah \\
\hline 2 & Minor & $\begin{array}{l}\text { Cidera Ringan }-\quad \text { kerugian finansial } \\
\text { memerlukan perawatan P3K langsung ditempat }\end{array}$ \\
\hline 3 & Moderate & $\begin{array}{l}\text { Cidera Sedang }- \text { kerugian finansial cukup tingg } \\
\text { diperlukan perawatan medis ditempat karna hilangnya fungs } \\
\text { anggota tubuh untuk sementara waktu }\end{array}$ \\
\hline 4 & Major & $\begin{array}{l}\text { Cidera Berat }- \text { kerugian finansial tingg } \\
\text { diperlukan pengobatan medis karna cacat fungsi tubuh secara } \\
\text { total sehingga menganggu proses produksi }\end{array}$ \\
\hline 5 & Catastrophic & $\begin{array}{l}\text { Kejadian Fatal - kerugian finansial sangat tingg } \\
\text { Terjadi kasus kematian, keracunan dengan efek gangguan } \\
\text { yang besar dan berdampak terhadap berhentinya seluruh } \\
\text { kegiatan }\end{array}$ \\
\hline
\end{tabular}

Sumber : AS/NZS 4360 (1999)

Setelah menentukan nilai likelihood dan consequence maka tahap selanjutnya menghitung nilai risiko dengan perhitungan rata-rata antara pembagian tingkat kemungkinan terjadinya bahaya dan tingkat keparahan dengan jumlah responden untuk memudahkan dalam perhitungan nilai risiko [13]. Adapun untuk mendapatkan nilai level risiko menggunakan rumus sebagai berikut :

$$
\text { Risk }=\text { Likelihood } x \text { Consequence } \text {. }
$$

Evaluasi risiko dapat dilakukan dengan bantuan skala risk matrix untuk mengklasifikasikan level risiko bahaya [14]. Adapun skala risk matrix ditabulasikan di Tabel 3, sedangkan untuk penjelasan dari level risiko ditampilkan di Tabel 4. 
Tabel 3. Skala risk matriks (tingkat risiko)

\begin{tabular}{lccccc}
\hline \multirow{4}{*}{ Likelihood } & \multicolumn{5}{c}{ Consequence } \\
\cline { 2 - 6 } & 1 & 2 & 3 & 4 & 5 \\
5 (Almost Certain) & Insignificant & Minor & Moderate & Major & Catastrophic \\
4 (Likely) & High & High & Extreme & Extreme & Extreme \\
3 (Moderate) & Moderate & High & High & Extreme & Extreme \\
2 (Unlikely) & Low & Moderate & High & Extreme & Extreme \\
1 (Rare) & Low & Low & Moderate & High & Extreme \\
\hline
\end{tabular}

Sumber : Standards Australia License/New Zealand Standard (1999)

Tabel 4. Kategori risk matriks (tingkat risiko)

\begin{tabular}{|c|c|c|c|}
\hline Simbol & Deskripsi & Keterangan & Tindakan \\
\hline E & $\begin{array}{c}\text { Extreme Risk } \\
\text { (Risiko sangat tinggi) }\end{array}$ & Aktivitas harus dihentikan & $\begin{array}{l}\text { Segera dilakukan tindakan } \\
\text { perbaikan }\end{array}$ \\
\hline $\mathrm{H}$ & $\begin{array}{c}\text { High Risk } \\
\text { (Risiko tinggi) }\end{array}$ & $\begin{array}{l}\text { Aktivitas tidak boleh } \\
\text { dilaksanakan sampai bahaya } \\
\text { sudah direduksi }\end{array}$ & $\begin{array}{llr}\text { Mendapatkan } & \text { perhatian } \\
\text { manajemen dan tindakan } & \text { denanganan dengan APD } \\
\text { lengkap } & & \\
\text { lengan } & \end{array}$ \\
\hline M & $\begin{array}{l}\text { Moderate Risk } \\
\text { (Risiko sedang) }\end{array}$ & $\begin{array}{l}\text { Dibutuhkan langkah untuk } \\
\text { meminimalisir risiko }\end{array}$ & $\begin{array}{l}\text { Menambah peralatan } \\
\text { pengamanan, perhatian serius } \\
\text { dan prosedur serta } \\
\text { menentukan tanggung jawab } \\
\text { manajemen }\end{array}$ \\
\hline $\mathrm{L}$ & $\begin{array}{c}\text { Low Risk } \\
\text { (Risiko rendah) }\end{array}$ & $\begin{array}{l}\text { Risiko masih dapat diterima } \\
\text { oleh perusahaan }\end{array}$ & $\begin{array}{l}\text { pengawasan prosedur secara } \\
\text { rutin }\end{array}$ \\
\hline
\end{tabular}

3. Pengendalian Risiko (Risk Control), yaitu langkah untuk menangani risiko yang ada di lingkungan kerja dengan cara menentukan ukuran prioritas dan diurutkan sesuai level risiko sebagai alat bantu memitigasi risiko (hirarki pengendalian risiko) [15]. Pada tahap ini menentukan keseluruhan dari sistem manajemen risiko dan menentukan apakah kejadian dan potensi kejadion risiko dan konsekuensi bahaya yang ada masuk dalam kategori dapat diterima atau tidak [16]. OHSAS 18001 : 2007 memberikan pedoman hirarki pengendalian risiko, sebagai berikut : Elimination, Substitution, Engineering Control, Adiminstrative Control and Personal Protective Equipment

\section{Hasil dan Pembahasan}

Temuan dan analisis lebih lanjut pada sub bab ini didapatkan data dengan melakukan observasi, wawancara dan penyebaran kuisioner kepada kepala departemen dan pekerja di PT ABC. Adapun total responden berjumlah 7 orang tenaga kerja yang sudah expert dalam melakukan analisis bahaya dan risiko di bidang electrical \& instrumen. Adapun yang didapatkan adalah data terkait aktivitas, rincian kegiatan, potensi bahaya dan risiko yang ada di PT. ABC pada department of electrical \& instrumen yang kemudian dilakukan peniaian risiko oleh responden langsung, adapun hasil identifikasi dan penilaian responden ditampilkan di Tabel 5.

Tabel 5. Ringkasan identifikasi bahaya, penilaian risiko dan penentuan level risiko

\begin{tabular}{|c|c|c|c|c|c|c|c|}
\hline \multirow[b]{2}{*}{ Aktivitas } & \multirow[b]{2}{*}{$\begin{array}{l}\text { Rincian } \\
\text { Kegiatan }\end{array}$} & \multirow[b]{2}{*}{ Potensi Bahaya } & \multirow[b]{2}{*}{ Risiko } & \multicolumn{3}{|c|}{ Penilaian risiko } & \multirow{2}{*}{$\begin{array}{l}\text { Level } \\
\text { Risiko }\end{array}$} \\
\hline & & & & $\begin{array}{l}\text { Tingkat } \\
\text { Kejadian }\end{array}$ & $\begin{array}{c}\text { Tingkat } \\
\text { Keparahan }\end{array}$ & $\begin{array}{l}\text { Nilai } \\
\text { Risiko }\end{array}$ & \\
\hline & \multirow{3}{*}{$\begin{array}{l}\text { Pemasangan } \\
\text { gardu induk }\end{array}$} & $\begin{array}{l}\text { Pekerja tersengat } \\
\text { aliran listrik }\end{array}$ & $\begin{array}{l}\text { Luka bakar, } \\
\text { gagal kerja } \\
\text { jantung, }\end{array}$ & 4 & 2 & 8 & $\mathrm{H}$ \\
\hline & & $\begin{array}{l}\text { Kebakaran pada } \\
\text { gardu induk }\end{array}$ & $\begin{array}{l}\text { Luka bakar, } \\
\text { kematian }\end{array}$ & 2 & 5 & 10 & $\mathrm{E}$ \\
\hline & & $\begin{array}{l}\text { Terjatuh karna } \\
\text { hilangnya } \\
\text { konsentrasi }\end{array}$ & $\begin{array}{l}\text { Patah tulang, } \\
\text { memar \& lecet } \\
\text { di tubuh }\end{array}$ & 2 & 3 & 6 & M \\
\hline
\end{tabular}




\begin{tabular}{|c|c|c|c|c|c|c|c|}
\hline \multirow{6}{*}{$\begin{array}{l}\text { Instalasi } \\
\text { Tegangan } \\
\text { Tinggi }\end{array}$} & \multirow{2}{*}{$\begin{array}{l}\text { Instalasi } \\
\text { jaringan } \\
\text { transmisi }\end{array}$} & $\begin{array}{l}\text { Tersengat listrik saat } \\
\text { pemeliharaan gardu } \\
\text { di titik sambung }\end{array}$ & $\begin{array}{l}\text { Kematian, } \\
\text { hilang } \\
\text { kesadaran, }\end{array}$ & 3 & 2 & 6 & M \\
\hline & & $\begin{array}{l}\text { Terjadi ledakan } \\
\text { karna kerusakan } \\
\text { kabel power induk }\end{array}$ & $\begin{array}{l}\text { Luka bakar, } \\
\text { kematian, } \\
\text { iritasi kulit }\end{array}$ & 2 & 5 & 10 & $\mathrm{E}$ \\
\hline & \multirow[t]{2}{*}{$\begin{array}{c}\text { Instalasi rak } \\
\text { kabel }\end{array}$} & $\begin{array}{l}\text { Kebakaran karna } \\
\text { koneksi kabel } \\
\text { terkelupas }\end{array}$ & $\begin{array}{l}\text { Luka bakar, } \\
\text { iritasi kulit }\end{array}$ & 2 & 4 & 8 & $\mathrm{H}$ \\
\hline & & $\begin{array}{l}\text { Pekerja tertimpa rak } \\
\text { kabel }\end{array}$ & $\begin{array}{l}\text { Patah tulang } \\
\text { Luka memar, }\end{array}$ & 3 & 2 & 6 & $\mathrm{M}$ \\
\hline & \multirow{2}{*}{$\begin{array}{c}\text { Pemasangan } \\
\text { kabel daya } \\
\text { kontrol }\end{array}$} & $\begin{array}{l}\text { Sentuhan terhadap } \\
\text { tergangan tinggi }\end{array}$ & $\begin{array}{l}\text { Hilangnya } \\
\text { kesadaran }\end{array}$ & 4 & 1 & 4 & M \\
\hline & & $\begin{array}{l}\text { Terjatuh dari tangga } \\
\text { saat bekerja di } \\
\text { ketinggian }\end{array}$ & $\begin{array}{l}\text { Patah tulang, } \\
\text { memar, lecet } \\
\text { di tubuh }\end{array}$ & 1 & 3 & 3 & M \\
\hline \multirow{4}{*}{$\begin{array}{l}\text { Instalasi } \\
\text { Tegangan } \\
\text { Rendah }\end{array}$} & $\begin{array}{l}\text { Pemutusan } \\
\text { arus L/V }\end{array}$ & $\begin{array}{l}\text { Pekerja tersengat } \\
\text { aliran listrik }\end{array}$ & $\begin{array}{l}\text { Luka bakar, } \\
\text { kematian }\end{array}$ & 4 & 1 & 4 & M \\
\hline & \multirow{2}{*}{$\begin{array}{l}\text { Instalasi } \\
\text { penerangan, } \\
\text { alarm } \\
\text { kebakaran }\end{array}$} & $\begin{array}{l}\text { Tertimpa ranting } \\
\text { pohon/tiang saat } \\
\text { bekerja }\end{array}$ & $\begin{array}{l}\text { Patah tulang, } \\
\text { luka pada } \\
\text { tubuh }\end{array}$ & 3 & 2 & 6 & M \\
\hline & & $\begin{array}{l}\text { Terjatuh dari } \\
\text { ketinggian karna } \\
\text { kelalaian pekerja }\end{array}$ & $\begin{array}{l}\text { Pingsan, patah } \\
\text { tulang }\end{array}$ & 2 & 2 & 4 & $\mathrm{~L}$ \\
\hline & $\begin{array}{l}\text { Grounding } \\
\text { System }\end{array}$ & $\begin{array}{l}\text { Pekerja tersengat } \\
\text { aliran listrik }\end{array}$ & Luka bakar & 3 & 2 & 6 & $\mathrm{M}$ \\
\hline \multirow{2}{*}{$\begin{array}{l}\text { Instalasi } \\
\text { Instrumen }\end{array}$} & $\begin{array}{l}\text { Instalasi } \\
\text { sistem } \\
\text { perpipaan }\end{array}$ & $\begin{array}{l}\text { Kebakaran akibat } \\
\text { korsleting listrik }\end{array}$ & $\begin{array}{l}\text { Luka bakar, } \\
\text { kematian, } \\
\text { iritasi kulit }\end{array}$ & 2 & 2 & 4 & $\mathrm{~L}$ \\
\hline & $\begin{array}{l}\text { Instalasi } \\
\text { kabel } \\
\text { lapangan \& } \\
\text { utama }\end{array}$ & $\begin{array}{l}\text { Pekerja tersengat } \\
\text { aliran listrik }\end{array}$ & $\begin{array}{l}\text { Luka bakar, } \\
\text { kematian }\end{array}$ & 4 & 3 & 12 & $\mathrm{H}$ \\
\hline
\end{tabular}

Sumber : Hasil observasi, wawancara dan kuisioner, 2020

Pada Tabel 5 dapat diketahui bahwa ditemukan 15 potensi bahaya dari 9 aktivitas yang dilakukan di tempat kerja. Adapun terdapat 2 kemungkinan bahaya yang memiliki tingkatan risiko rendah, 8 kemungkinan terjadi bahaya termasuk dalam tingkatan risiko sedang, 3 kemungkinan terjadi bahaya dikategorikan pada tingkatan risiko tinggi dan 2 potensi bahaya termasuk dalam kategori level risiko sangat tinggi. Rincian kegiatan yang termasuk dalam kategori medium dan high haruslah segera dilakukan pengendalian risiko untuk meminimalisir kecelakaan kerja terjadi dan para pekerja selalu dalam kondisi aman, selamat dan sehat dari bahaya kecelakaan kerja. Berdasarkan identifikasi bahaya pada Tabel 5 dapat diketahui bahwa potensi bahaya dengan level risiko sangat tinggi terjadi pada rincian kegiatan pemasangan gardu induk dan instalasi jaringan transmisi, dimana kedua kegiatan tersebut tergolong pada aktivitas instalasi tegangan tinggi.

Tahapan selanjutnya adalah pengelolaan kemungkinan dan kejadian risiko bahaya yang telah ditentukan tersebut agar langkah-langkah preventive pencegahan kerja dapat diimplementasikan di lapangan. Hasil dari identifikasi potensi bahaya, penilaian risiko dan penentuan level risiko akan diberikan risk control berupa rekomendasi terhadap perusahaan. Adapun rekomendasi ini berupa langkah untuk mereduksi potensi bahaya berdasar hirarki pengendalian risiko, yaitu eliminasi, substitusi, pengendalian teknik, pengendalian administartif dan APD, adapun data hasil brainstorming dengan kepala departemen HSE PT. ABC dapat dilihat pada Tabel 6. Kegiatan brainstorming dilaksanakan sebanyak 5 kali, dimana 2 kali dilakukan secara offline sedangkan sisanya dilakukan secara online. 
Tabel 6. Rekomendasi pengendalian risiko

\begin{tabular}{|c|c|c|c|c|c|c|}
\hline \multirow[b]{2}{*}{$\begin{array}{l}\text { Rincian } \\
\text { Kegiatan }\end{array}$} & \multirow[b]{2}{*}{ Potensi Bahaya } & \multicolumn{5}{|c|}{ Pengendalian Risiko } \\
\hline & & $\begin{array}{c}\text { Elimi } \\
\text { nasi }\end{array}$ & $\begin{array}{l}\text { Substi } \\
\text { tusi }\end{array}$ & $\begin{array}{l}\text { Pengendalian } \\
\text { Teknik }\end{array}$ & $\begin{array}{l}\text { Pengendalian } \\
\text { Administratif }\end{array}$ & APD \\
\hline \multicolumn{7}{|c|}{ 1. Instalasi Tegangan Tinggi } \\
\hline \multirow[b]{2}{*}{$\begin{array}{l}\text { Pemasangan } \\
\text { gardu induk }\end{array}$} & $\begin{array}{l}\text { Pekerja tersengat } \\
\text { aliran listrik }\end{array}$ & & & $\begin{array}{l}\text { Menambah } \\
\text { peralatan instalasi } \\
\text { tegangan tinggi }\end{array}$ & $\begin{array}{l}\text { Melakukan pengecekan } \\
\text { kondisi kabel dan alat, } \\
\text { rutin melakukan } \\
\text { management safety } \\
\text { patrol } \\
\end{array}$ & \multirow{2}{*}{$\begin{array}{l}\text { Memakai sarung } \\
\text { tangan \& sepatu } \\
\text { safety yang } \\
\text { sesuai standar }\end{array}$} \\
\hline & $\begin{array}{l}\text { Kebakaran pada } \\
\text { gardu induk }\end{array}$ & & & $\begin{array}{l}\text { Membuat tambahan } \\
\text { pengendalian } \\
\text { khusus dalam } \\
\text { penanganan gardu } \\
\text { induk } \\
\end{array}$ & $\begin{array}{l}\text { Memberikan sanksi } \\
\text { terhadap karyawan } \\
\text { yang tidak memakai } \\
\text { APD lengkap }\end{array}$ & \\
\hline \multirow{3}{*}{$\begin{array}{l}\text { Instalasi } \\
\text { jaringan } \\
\text { transmisi }\end{array}$} & $\begin{array}{c}\text { Terjatuh dari } \\
\text { tangga/tiang karna } \\
\text { hilangnya } \\
\text { konsentrasi } \\
\end{array}$ & & & $\begin{array}{c}\text { Menambah } \\
\text { pelayanan } \\
\text { pemeriksaan } \\
\text { sebelum bekerja } \\
\end{array}$ & $\begin{array}{c}\text { Melakukan pengawasan } \\
\text { SOP }\end{array}$ & $\begin{array}{l}\text { Memakai APD } \\
\text { (anchor test, full } \\
\text { body harnesses) } \\
\text { secara tepat }\end{array}$ \\
\hline & $\begin{array}{l}\text { Tersengat tegangan } \\
\text { listrik di titik } \\
\text { sambung gardu } \\
\end{array}$ & & & $\begin{array}{c}\text { Menambah } \\
\text { peralatan instalasi } \\
\text { tegangan tinggi }\end{array}$ & $\begin{array}{c}\text { Melakukan proses } \\
\text { penyambungan jaringan } \\
\text { digardu sesuai SOP }\end{array}$ & \multirow[b]{2}{*}{$\begin{array}{l}\text { Memakai APD } \\
\text { lengkap yang } \\
\text { berisolasi tinggi }\end{array}$} \\
\hline & $\begin{array}{c}\text { Terjadi ledakan } \\
\text { karna kerusakan } \\
\text { kabel power induk }\end{array}$ & & & $\begin{array}{l}\text { Membuat tambahan } \\
\text { pengendalian } \\
\text { khusus dalam } \\
\text { penanganan kabel } \\
\text { induk } \\
\end{array}$ & $\begin{array}{l}\text { Melakukan pemutusan } \\
\text { berkala pada arus listrik } \\
\text { sesuai prosedur }\end{array}$ & \\
\hline \multirow{2}{*}{$\begin{array}{l}\text { Instalasi rak } \\
\text { kabel }\end{array}$} & $\begin{array}{l}\text { Kebakaran karna } \\
\text { koneksi kabel } \\
\text { terkelupas }\end{array}$ & & & $\begin{array}{l}\text { Mengganti setiap } \\
\text { peralatan instalasi } \\
\text { yang rusak }\end{array}$ & $\begin{array}{l}\text { Memberikan sanksi } \\
\text { terhadap karyawan } \\
\text { yang tidak memakai } \\
\text { APD lengkap }\end{array}$ & $\begin{array}{l}\text { Memakai APD } \\
\text { lengkap yang } \\
\text { berisolasi tinggi }\end{array}$ \\
\hline & $\begin{array}{l}\text { Pekerja tertimpa } \\
\text { rak kabel }\end{array}$ & & & $\begin{array}{c}\text { Penambahan } \\
\text { penggunaan alat } \\
\text { katrol yang sesuai } \\
\text { dengan berat rak } \\
\text { kabel } \\
\end{array}$ & $\begin{array}{l}\text { Briefing sebelum } \\
\text { bekerja mengenai } \\
\text { bahaya pekerjaan }\end{array}$ & $\begin{array}{l}\text { Menggunakan } \\
\text { helm safety }\end{array}$ \\
\hline \multirow{2}{*}{$\begin{array}{l}\text { Pemasangan } \\
\text { kabel daya } \\
\text { kontrol }\end{array}$} & $\begin{array}{l}\text { Sentuhan terhadap } \\
\text { tergangan tinggi }\end{array}$ & & & $\begin{array}{c}\text { Menambah } \\
\text { kegiatan internal } \\
\text { safety refreshment } \\
\text { untuk peningkatan } \\
\text { kompetensi } \\
\text { karyawan } \\
\end{array}$ & $\begin{array}{c}\text { Melakukan pengecekan } \\
\text { kondisi kabel secara } \\
\text { rutin }\end{array}$ & $\begin{array}{l}\text { Memakai APD } \\
\text { lengkap yang } \\
\text { berisolasi tinggi }\end{array}$ \\
\hline & $\begin{array}{l}\text { Terjatuh dari } \\
\text { tangga saat bekerja } \\
\text { di ketinggian }\end{array}$ & & & & $\begin{array}{c}\text { Briefing sebelum } \\
\text { bekerja, melakukan } \\
\text { pekerjaan sesuai SOP }\end{array}$ & $\begin{array}{l}\text { Memakai APD } \\
\text { (full body } \\
\text { harnesses) } \\
\text { secara tepat }\end{array}$ \\
\hline \multicolumn{7}{|c|}{ 2. Instalasi Tegangan Rendah } \\
\hline $\begin{array}{l}\text { Pemutusan } \\
\text { arus L/V }\end{array}$ & $\begin{array}{l}\text { Pekerja tersengat } \\
\text { aliran listrik }\end{array}$ & & & $\begin{array}{c}\text { Menambah } \\
\text { kegiatan simulasi } \\
\text { penanganan } \\
\text { jaringan listrik }\end{array}$ & $\begin{array}{c}\text { Melakukan } \\
\text { pembebasan arus listrik } \\
\text { sesuai prosedur }\end{array}$ & $\begin{array}{l}\text { Memakai APD } \\
\text { lengkap yang } \\
\text { berisolasi tinggi }\end{array}$ \\
\hline \multirow{2}{*}{$\begin{array}{l}\text { Instalasi } \\
\text { penerangan, } \\
\text { alarm } \\
\text { kebakaran }\end{array}$} & $\begin{array}{c}\text { Tertimpa ranting } \\
\text { pohon/tiang saat } \\
\text { bekerja }\end{array}$ & & & & $\begin{array}{c}\text { Melakukan pengecekan } \\
\text { kondisi ranting/tiang } \\
\text { sebelum perbaikan }\end{array}$ & $\begin{array}{l}\text { Memakai helm } \\
\text { safety }\end{array}$ \\
\hline & $\begin{array}{l}\text { Terjatuh dari } \\
\text { ketinggian karna } \\
\text { kelalaian pekerja } \\
\end{array}$ & & & $\begin{array}{c}\text { Menambah } \\
\text { prosedur SOP yang } \\
\text { tepat } \\
\end{array}$ & $\begin{array}{l}\text { Briefing sebelum } \\
\text { bekerja mengenai } \\
\text { bahaya pekerjaan }\end{array}$ & $\begin{array}{l}\text { Menggunakan } \\
\text { safety belt } \\
\text { secara lengkap }\end{array}$ \\
\hline $\begin{array}{l}\text { Grounding } \\
\text { System }\end{array}$ & $\begin{array}{l}\text { Pekerja tersengat } \\
\text { aliran listrik }\end{array}$ & & & $\begin{array}{c}\text { Penambahan } \\
\text { penggunaan alat } \\
\text { pemasangan } \\
\text { Grounding System }\end{array}$ & $\begin{array}{c}\text { Melakukan } \\
\text { implementasi instruksi } \\
\text { kerja }\end{array}$ & $\begin{array}{l}\text { Menggunakan } \\
\text { APD khusus } \\
\text { Grounding } \\
\text { System }\end{array}$ \\
\hline
\end{tabular}




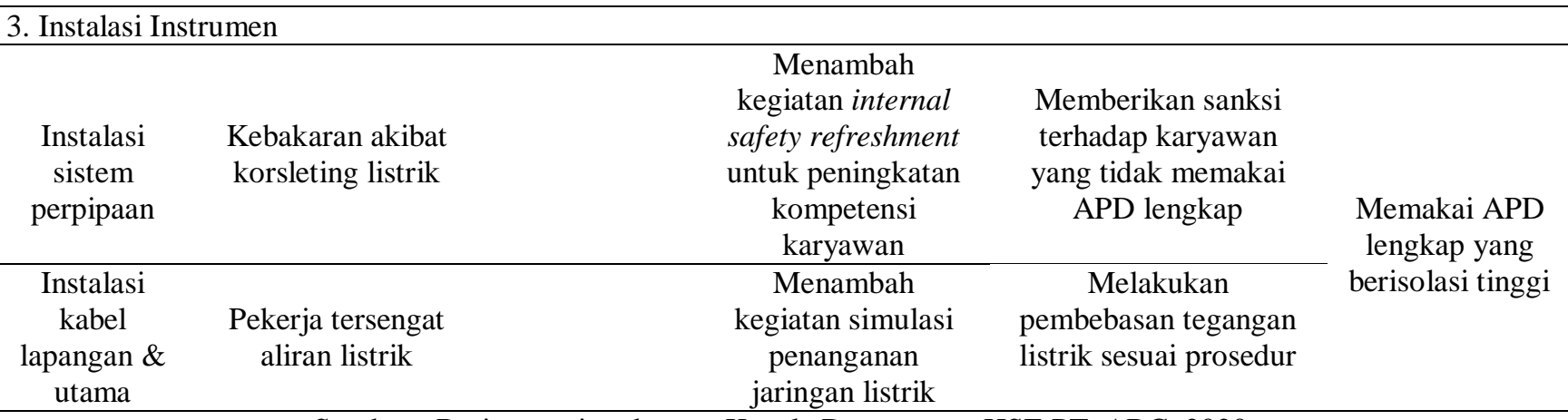

Sumber : Brainstorming dengan Kepala Departemen HSE PT. ABC, 2020

Berdasarkan rekomendasi yang ditabulasikan tersebut maka dapat diketahui bahwa pengendalian risiko diberikan pada masing-masing potensi bahaya yang ada dengan harapan rekomendasi ini dapat mengurangi dan mencegah terjadinya kecelakaan kerja. langkah rekomendasi risk control berkaitan dengan pengendalian teknis, pengendalian administratif dan APD sedangkan untuk eliminasi dan substitusi tidak dilakukan karena kondisi aktual perusahaan yang tidak memungkinkan untuk melakukan pengendalian tersebut.

Skenario implementasi dari rekomendasi risk control dapat dilakukan dan di breakdown menjadi 3 periode yaitu implementasi jangka pendek dengan waktu kurang dari 1 tahun, implementasi jangka menengah dalam kurun waktu 1-3 tahun dan implementasi jangka jangka panjang lebih dari 3 tahun. Untuk periode jangka pendek dapat menerapkan rekomendasi yang diberikan dengan mengutamakan risiko dengan level risiko tinggi dan sangat tinggi. Sedangkan untuk peiode jangka menengah dapat melakukan pembaharuan training secara berkala dan menerapkan rekomendasi risk control dengan level risiko sedang. Dan untuk implementasi jangka panjang dapat melakukan skenario risk control yang memiliki level risiko rendah.

\section{Kesimpulan dan Saran}

Simpulan dari analisis data hasil klarifikasi di PT. ABC ditemukan 15 potensi bahaya dari 9 aktivitas pekerjaan di PT. ABC terutama di bidang electrical \& instrumen. Hasil penilaian risiko ditemukan peluang dari 15 potensi bahaya yang ada terdapat dua bahaya termasuk klasifikasi tingkat extreme risk, tiga bahaya termasuk dalam kategori level high risk, delapan bahaya termasuk dalam kategori level moderate risk dan dua bahaya termasuk dalam kategori level low risk. Dari hasil evaluasi level risiko diberikan rekomendasi pengendalian risiko terhadap keseluruhan potensi bahaya dengan level extreme risk, high risk, moderate risk and low risk berdasar pedoman hirarki pengendalian risiko.

Hasil penelitian ini juga merekomendasikan usulan untuk bahan pertimbangan meminimalisir kecelakaan kerja. Bagi pimpinan perusahaan jasa konstruksi perlu melakukan sosialisasi dan membudayakan pentingnya K3 untuk tenaga kerja yang harus dimulai dari diri sendiri. Bagi departemen K3 harus selalu melakukan monitoring untuk memastikan bahwa penerapan K3 di lingkungan kerja sudah berjalan sesuai SOP yang ada agar tenaga kerja terhindar dari kecelakaan kerja. Bagi para tenaga kerja hendaknya selalu memakai alat pelindung diri (APD) yang tepat dan sesuai standar yang ada agar tetap di kondisi aman, selamat dan sehat dari bahaya kecelakaan kerja.

Penelitian ini hanya membahas tentang implementasi K3 menggunakan metode HIRARC dengan melakukan identifikasi bahaya, penilaian risiko dan rekomendasi pengendalian risiko dari potensi bahaya yang ditemukan guna meningkatkan keselamatan dan kesehatan pekerja dan tidak membahas permasalahan implementasi pada aturan manajemen perusahaan mengenai pengelolaan keselamatan dan kesehatan kerja (SMK3). Penelitian selanjutnya fokus pada penambahan jumlah rekomendasi risk control, implementasi dan pemantauan risk control ditempat kerja secara langsung.

\section{Referensi}

[1] T. Ihsan, A. Safitri, dan D. P. Dharossa, "Analisis Risiko Potensi Bahaya Dan Pengendaliannya Dengan Metode HIRADC Pada PT.Igasar Kota Padang Sumatera Barat," Serambi Engineering, Vol. V, No. 02, Pp. 1063-1069, April 2020.

[2] G. P. Humairoh dan R. D. E. Putra, "Analisa Faktor-Faktor Yang Berhubungan Dengan Kelelahan Fisik Karyawan (Studi Kasus Pt.X)," Serambi Engineering, Vol. V, No. 03, Pp. 1177-1187, Juli 2020. 
[3] P. Giananta, J. Hutabarat, And Soemanto, "Analisa Potensi Bahaya Dan Perbaikan Sistem Keselamatan Dan Kesehatan Kerja Menggunakan Metode Hirarc Di PT Boma Bisma Indra," Jurnal Valtech (Jurnal Mahasiswa Teknik Industri), Vol. 3, No. 2, Pp. 106-110, 2020.

[4] Anizar, Teknik Keselamatan Dan Kesehatan Kerja Di Industri. Yogyakarta: Graha Ilmu, 2012.

[5] A. Setiyoso, T. I. Oesma, dan M. Yusuf, "Analisis Potensi Kecelakaan Akibat Kerja Menggunakan Job Safety Analysis (JSA) Dengan Pendekatan Hazard Identification Risk Assessment And Risk Control (Hirarc)," Jurnal Rekavasi (Jurnal Rekayasa Dan Inovasi Teknik Industri), Vol. 07, No. 01, Pp. 1-7, Mei 2019.

[6] I. Aryati, "Evaluasi Penerapan Keselamatan Dan Kesehatan Kerja (K3) Pada Proyek Bangunan Gedung Di Kabupaten Cirebon," Jurnal Teknik Sipil Dan Perencanaan, Vol. 19, No. 1, Pp. 1-8, 2017.

[7] R. Alfatiyah, "Analisis Manajemen Risiko Keselamatan Dan Kesehatan Kerja Dengan Menggunakan Metode Hirarc Pada Pekerjaan Seksi Casting," Jurnal Sintek (Jurnal Mesin Teknologi), Vol. 11, No. 2, Pp. 88-101, Desember 2017.

[8] A. Efendi, M. Yusuf, dan T. I. Oesman, "Identifikasi Bahaya Kerja Menggunakan Hazard Identification And Risk Assesment (Hira) Dan Postur Kerja Untuk Mengurangi Kecelakaan Kerja Pada Departemen Produksi Dengan Rapid Upper Limb Assesment (Rula) Studi Kasus Pada: Pt. Medari Karya Mulia," Jurnal Rekavasi (Rekayasa \& Inovasi Teknik Industri), Vol. 06, No. 02, Pp. 82-90, Desember 2018.

[9] Ohsas 18001:2007, Occupational Health And Safety Assessment Series - Guideline For The Implementation Of Ohsas 18001., 1999.

[10] I. W. G. E. Triswandana dan N. K. Armaeni, "Penilaian Risiko K3 Konstruksi Dengan Metode Hirarc," Jurnal Ukarst (Universitas Kediri Riset Teknik Sipil), Vol. 04, No. 1, Pp. 97-108, 2020.

[11] L. Aulia dan A. R. Hermawanto, "Analisis Risiko Keselamatan Kerja Pada Bagian Pelayanan Distribusi Listrik Dengan Metode Hirarc (Studi Kasus Di Pt. Haleyora Power)," Sistemik (Jurnal Ilmiah Nasional Bidang Ilmu Teknik), Vol. 08, No. 01, Pp. 20-24, Juni 2020.

[12] O. A. Koreawan dan M. Basuki, "Identifikasi Bahaya Bekerja Dengan Pendekatan Hazard Identification Risk Assessment And Risk Control (Hirarc) Di PT. Prima Alloy Steel Universal," Seniati (Seminar Nasional Inovasi Dan Aplikasi Teknologi Di Industri), Vol. 5, No. 1, Pp. 161-165, Februari 2019.

[13] L. D. Fathimahhayati, M. R. Wardana, dan N. A. Gumilar, "Analisis Risiko K3 Dengan Metode Hirarc Pada Industri Tahu Dan Tempe Kelurahan Selili, Samarinda," Jurnal Rekavasi (Rekayasa Dan Inovasi Teknik Industri), Vol. 07, No. 01, Pp. 62-70, Mei 2019.

[14] Standards Australia License/New Zealand Standard, Az/Nzs 4360:1999 Risk Management. Brisbane: Standards Association Of Australia, Po Box 1055, Strathfield Nsw 2135, 1999.

[15] F. Ramadhan, "Analisis Kesehatan Dan Keselamatan (K3) Menggunakan Metode Hazard Identification Risk Assessment And Risk Control (HIRARC)," Senasset (Seminar Nasional Riset Terapan), Pp. 164-169, November 2017.

[16] S. N. Trisaid, "Analisis Risiko Kecelakaan Kerja Pada Kegiatan Rig Service Menggunakan Metode Hirarc Dengan Pendekatan Fta," Jurnal Ilmiah Teknik Industri, Vol. 8, No. 01, Pp. 25-33, 2020. 